\title{
Erratum to: Prenatal expectations in Mexican American women: development of a culturally sensitive measure
}

\author{
Jenna L. Gress-Smith • Danielle S. Roubinov • \\ Rika Tanaka • Keith Crnic • Nancy Gonzales • \\ Craig Enders • Linda J. Luecken
}

Published online: 8 June 2013

(C) Springer-Verlag Wien 2013

Erratum to: Arch Womens Ment Health

DOI: 10.1007/s00737-013-0350-2

The original version of this article unfortunately contained a spelling error of an author's last name. The name "Keith Crnic" is now corrected in the author group of this article. dx.doi.org/10.1007/s00737-013-0350-2.

J. L. Gress-Smith $(\bowtie) \cdot$ D. S. Roubinov $\cdot$ R. Tanaka $\cdot$ K. Crnic $\cdot$ N. Gonzales $\cdot$ C. Enders $\cdot$ L. J. Luecken

Department of Psychology, Arizona State University, $950 \mathrm{~S}$

McAllister St., P.O. Box 871104, Tempe, AZ 85287-1104, USA

e-mail: jgress@asu.edu 